AperTO - Archivio Istituzionale Open Access dell'Università di Torino

\title{
Prediction of Cyclic Fatigue Life of Nickel-Titanium Rotary Files by Virtual Modeling and Finite Elements Analysis
}

\section{This is the author's manuscript}

Original Citation:

Availability:

This version is available http://hdl.handle.net/2318/1558798

since 2016-03-29T16:17:25Z

Published version:

DOI:10.1016/j.joen.2015.07.010

Terms of use:

Open Access

Anyone can freely access the full text of works made available as "Open Access". Works made available under a Creative Commons license can be used according to the terms and conditions of said license. Use of all other works requires consent of the right holder (author or publisher) if not exempted from copyright protection by the applicable law. 


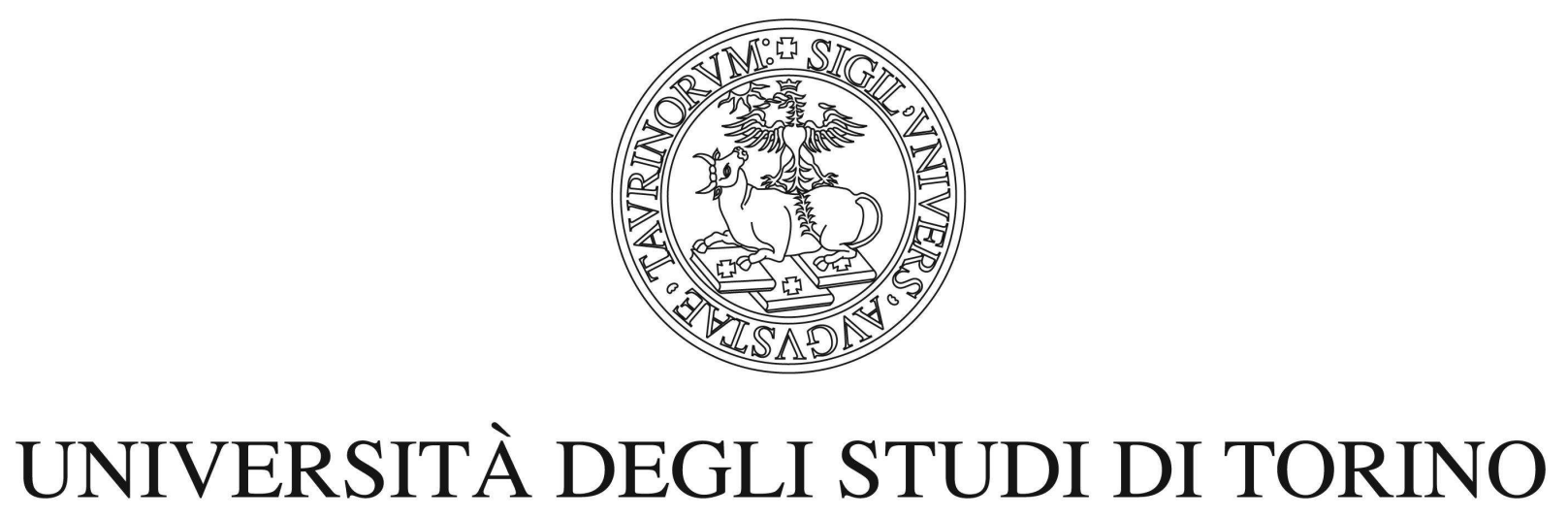

This is an author version of the contribution published on:

Questa è la versione dell'autore dell'opera:

J Endod. 2015 Nov;41(11):1867-70. doi: 10.1016/j.joen.2015.07.010. Epub 2015 Sep 9

The definitive version is available at:

La versione definitiva è disponibile alla URL:

http://www.sciencedirect.com/science/article/pii/S0099239915006603 


\title{
Prediction of Cyclic Fatigue Life of Nickel-Titanium Rotary Files by Virtual Modeling and Finite
}

\section{Elements Analysis}

\author{
Alessandro Scattina, MS, PhD,* Mario Alovisi, DDS, Davide Salvatore Paolino, MS, PhD,* \\ Damiano Pasqualini, DDS, Nicola Scotti, DDS, Giorgio Chiandussi, MS, PhD,* \\ and Elio Berutti, MD, DDS
}

\author{
From the *Department of Mechanical and Aerospace Engineering, Politecnico di Torino and \\ 'Division of Endodontics, Department of Surgical Sciences, University of Turin Dental School, Turin, \\ Italy.
}

Address requests for reprints to Dr Damiano Pasqualini, via Nizza, 230-10126 Torino, Italy. E-mail address: damiano. pasqualini@unito.it

\begin{abstract}
Introduction: The finite element method (FEM) has been proposed as a method to analyze stress distribution in nickel-titanium (NiTi) rotary instruments but has not been assessed as a method of predicting the number of cycles to failure (NCF). The objective of this study was to predict NCF and failure location of NiTi rotary instruments by FEM virtual simulation of an experimental nonstatic fatigue test. Methods: ProTaper Next (PTN) X1, X2, and X3 files (Dentsply Maillefer, Baillagues, Switzerland) ( $\mathrm{n}=20$ each) were tested to failure using a customized fatigue testing device. The device and file geometries were replicated with computer-aided design software. Computer-aided design geometries (geometric model) were imported and discretized (numeric model). The typical material model of an M-Wire alloy was applied. The numeric model of the device and file geometries were exported for finite element analysis (FEA). Multiaxial random fatigue methodology was used to analyze stress history and predict instrument life. Experimental data from PTN X2 and X3 were used for virtual model tuning through a reverse engineering approach to optimize material mechanical properties. Tuned material parameters were used to predict the average NCF and failure locations of PTN X1 by FEA; $t$ tests were used to compare FEA and experimental findings ( $\mathrm{P}<.05)$. Results: Experimental NCF and failure locations did not differ from those predicted with FEA $(\mathrm{P}=.098)$. Conclusions: File NCF and failure location may be predicted by FEA. Virtual design, testing, and analysis of file geometries could save considerable time and resources during instrument development. (J Endod 2015;41:1867-1870)
\end{abstract}

Key Words C-S criterion, finite element analysis, multiaxial random fatigue, nickel-titanium rotary instrument, virtual modeling

Since their introduction, nickel-titanium (NiTi) rotary instruments have considerably simplified endodontic practice by improving speed, accuracy, and safety during root canal shaping $(1,2)$. Continuous enhancements in the design and manufacture of NiTi rotary instruments have significantly reduced but not completely eliminated the occurrence of failure during canal shaping $(3,4)$. Although rare, breakage of NiTi rotary instruments may lead to incomplete chemomechanical treatment of the root canal system and hinder healing, particularly in the presence of preexisting apical radiolucency (5, 6). Furthermore, excessive removal of the tooth structure can occur during fragment elimination procedures $(5,6)$. Although many variables can contribute to instrument failure, the primary causes are cyclic bending fatigue and torsional overload. Torsional overload is related to the risk of taper lock, and its incidence might be reduced by performing a glide path and preliminary enlargement (7-9). However, NiTi instrument failures are mainly caused by cyclic bending fatigue, which occurs when a NiTi instrument rotates in a curved root canal (10-14). During rotation, the instrument material is alternatively subjected to compressive and tensile stresses (11). Such stresses may initiate crack 
formation and propagation, leading to eventual failure $(4,15)$. Instruments that fail because of bending fatigue usually exhibit no specific macroscopic patterns, and failure may occur without any visible warning $(1,5,16,17)$. Canal shape, instrument geometry, rotational speed, torque, instrument surface treatments, and the chemical composition of NiTi alloys are the main factors affecting the number of cycles to failure (NCF) of NiTi rotary instruments $(2,4,18-21)$. Standardized experimental conditions are not possible for extracted teeth (22), but several self-designed devices and methods have been used to assess the NCF of NiTi rotary instruments in vitro (22). However, there is no international standard for testing the cyclic fatigue behavior of endodontic rotary instruments in vitro (22). A 3-dimensional computerized approach based on the finite element method (FEM) (23-27) has been recently proposed to analyze stress distribution in bending fatigue. This approach takes cyclic loading conditions into consideration $(25,27)$ but makes no attempt to predict NCF.

The objective of this study was to assess the possibility of predicting the NCF and failure location of NiTi rotary instruments by the virtual simulation of an experimental fatigue test (nonstatic loading condition) using the FEM.

\section{Materials and Methods}

ProTaper Next (PTN) X1, X2, and X3 files ( $=20$ each), $25 \mathrm{~mm}$ in length, were tested to failure using a tempered steel fatigue testing device developed by Dentsply Maillefer (Baillagues, Switzerland), which produced a reproducible simulation of rotary instrumentation within a curved canal. Testing configurations adopted for every file type are reported in Figure 1 and Table 1. Testing configurations for file $\mathrm{X} 1$ and files $\mathrm{X} 2$ and $\mathrm{X} 3$ differ with respect to canal depth and the position of the curvature center of the component simulating the inner canal wall. The testing device is covered with a glass or steel element to prevent the file leaving the canal during rotation. Each file was inserted, leaving the noncutting tip outside the canal, and rotation initiated with an electric motor (X-Smart, Dentsply Maillefer) at the suggested settings (300 rpm, $5 \mathrm{Ncm})$. Time to failure was recorded and converted to NCF. Experimental tests were performed by Dentsply Maillefer; tested files were photographed with a digital camera after failure (Canon EOS 350D, 8 Mpx resolution, ISO 100, f 18, $1 / 60$ seconds; Canon, Tokyo, Japan), and failure locations were measured in millimeters from the tip of the instrument (image analysis, caliper).

The customized fatigue testing device and file geometries were computer replicated (Supplemental Video S1) with computer-aided design software (SolidWorks 2013; Dassault Systems, Waltham, MA). Computer-aided design geometries (geometric model) were imported in a prepost processor (Hypermesh 12.0; Altair, Troy, MI) and discretized (numeric model). The main body of each file was modeled with 18,000 brick elements, with an average size of $0.1 \mathrm{~mm}$ (Fig. 2). The tip and neck of the file were modeled with tetrahedral elements with the same average dimensions. The typical material model of an M-Wire alloy (NiTi alloy), taken from the literature (28), was applied. The testing device was modeled with 2000 shell element and was considered a rigid material. Contact between the file and the testing device was introduced with a penalty contact formulation implemented in LS-Dyna (LS-Dyna R7.1; Livermore, Livermore, CA). The penalty method introduces a force at the contact detection points that penetrates across the target surface with the purpose of eliminating penetration (29). The numeric model of the customized fatigue testing device and the file geometries were exported into the finite element solver (LS-Dyna R7.1) for finite element analyses (FEA). The FEA aimed to mimic the experimental test performed with the Maillefer customized fatigue testing device. The file, in rest configuration (straight file), was inserted into the testing device and then bent by the simulated canal walls (rigid shell elements). It was finally put into rotation at $300 \mathrm{rpm}$. The stress state in the brick elements of each file model was recorded every 0.2 seconds for 2 seconds (Supplemental Videos S2-S4). 
Traditional life prediction methods developed for uniaxial variable amplitude loading could not be used in this study because of the complexity of the stress-strain state and the loading history over time (multiaxial random loading). Element stress history must be analyzed by applying an appropriate multiaxial random fatigue (MRF) criterion. Few methodologies concerning MRF have been proposed, and research on the topic is still in progress. A recent MRF methodology, proposed by Carpinteri et al (30) and named the C-S criterion, was adopted in this study to analyze the stress history of each file element. The C-S criterion was implemented in Matlab 2014 (The MathWorks Inc, Natick, MA) with the assumption that the stress history recorded in the first 2 seconds was identically repeated until failure. The $\mathrm{C}-\mathrm{S}$ criterion was used to calculate the time to failure for each brick element and, as a consequence, to predict the file NCF (the minimum NCF in the file).

The mechanical properties of a material are not provided, and the influence of manufacturing surface defects cannot be evaluated a priori. As a consequence, a reverse engineering approach for model tuning was adopted to obtain the required information. Several material properties were taken into account through the Matlab model and were tuned to match the experimental NCF of PTN X2 and X3 files. Material parameters were altered through an optimization algorithm implemented in Matlab 2014 to reduce the difference between the file NCF obtained with FEM and the experimental NCF. The tuned material parameters were then used to predict the average NCF of PTN X1 file with FEA. Failure locations for each file type were recorded and compared with the failure locations of the files photographed after failure in the Maillefer customized fatigue testing device; $t$ tests were performed to compare FEA and experimental results $(\mathrm{P}=.05)$.

\section{Results}

The main results of the analyses are presented in Table 2. The NCF of PTN X2 and X3 files was used for the tuning of material parameters involved in the $\mathrm{C}-\mathrm{S}$ criterion. Their $\mathrm{P}$ values for the NCF were subsequently extremely large $(\mathrm{P}=.896$ and .787 , respectively). There was also no significance in the NCF of the PTN X1 file $(\mathrm{P}=.098)$. Therefore, no significant statistical difference was found between the experimental NCF and the NCF predicted by FEA.

In addition, no significant statistical difference was found between the experimental failure locations and the failure locations predicted by FEA $(\mathrm{P}=.148$ for PTN X1 file, $\mathrm{P}=.995$ for PTN X2 file, and $\mathrm{P}=.481$ for PTN X3 file).

Possible failure locations predicted with FEA, together with the experimental failure locations obtained from the photographed files, are shown in Figure 3. For every file type, vertical lines indicate $95 \%$ confidence intervals of the experimental failure locations, whereas the highlighted point denotes the location of the element with the smallest NCF where the predicted failure occurred.

\section{Discussion}

Multiaxial loading usually acts on NiTi rotary instruments during shaping $(31,32)$ as a result of the simultaneous presence of bending and torsion. Given a file type (geometry and material), the torsional overload largely depends on the preexisting root canal size and the apical force exerted during instrumentation, whereas the cyclic bending fatigue depends on unmodifiable anatomic factors such as the root canal radius and degree of curvature (22). File rotation around a curved axis (the axis of the file inserted into a curved canal root) leads to a continuously varying complex stress state including normal and shear components (15) and, therefore, to a fatigue phenomenon, which accounts for up to $90 \%$ of endodontic instrument mechanical failures $(2,33)$.

In the present study, FEA analysis was introduced as a virtual testing approach to predict mechanical behavior of the NiTi file. FEA is a numeric method that calculates the stress field in any file geometry according to the file material properties and the boundary loading conditions (27). Virtual testing results obtained by simulating the rotation of ProTaper Next X1, X2, and X3 instruments were compared with the experimental results obtained with a customized fatigue testing device. A reverse engineering approach was used to overcome the lack of information regarding the material behavior 
and the local stress concentration effects caused by manufacturing surface defects $(5,34,35)$.

The instrument stress state obtained by FEA was elaborated according to the C-S criterion proposed by Carpinteri et al (30) to calculate the NCF and failure location caused by cyclic bending fatigue. The C-S criterion is applicable when stresses are below the yield strength of the material (ie, no plasticity phenomena occur during load application). The applicability of the C-S criterion is not influenced by file rotation speed or, more generally, by the applied load frequency. The authors verified the applicability of the C-S criterion; for the analyzed cases, the stress state was far below the yield strength of the material, and, therefore, no plasticity occurred during load application.

Unknown material properties (eg, the normal stress fatigue limit and the shear stress fatigue limit) were required for the application of the $\mathrm{C}-\mathrm{S}$ criterion, and a reverse engineering approach was performed to estimate them. Material properties were modified and optimized to reduce the difference between the file NCF obtained with FEA and the NCF obtained with the fatigue testing device for ProTaper Next X2 and X3. The tuned parameters are specific for the material used to manufacture the analyzed files. The same parameters can be used for any FEA in which the file material is kept the same. If the file material changes, the material properties change and must be found through a further tuning process. The optimized material properties and the fatigue prediction model based on the C-S criterion were used to predict the NCF of the ProTaper Next X1.

The results presented here show that virtual simulation through FEA can be usefully adopted to predict the file NCF and the failure location. As a consequence, given the material properties obtained through the reverse engineering approach, FEA can be effectively used to virtually design new file geometries. Therefore, the FEA approach would potentially overcome the usual expensive trial and error approach based on repetitive prototype manufacturing and testing. This study shows the feasibility of numerically analyzing instrument geometries to predict the file NCF and location of failure. The evaluation of material mechanical properties through a reverse engineering approach based on a multiaxial random fatigue criterion allows the virtual verification of new file geometries toward cyclic bending fatigue failure. The virtual analysis of file behavior may lead to a considerable saving of time and resources during instrument development. The evaluation of the material properties through a reverse engineering approach could be avoided if the material properties and the manufacturing defects are properly characterized and taken into account.

\section{Acknowledgments}

The authors deny any conflicts of interest related to this study.

\section{Supplementary Material}

Supplementary material related to this article can be found at http://dx.doi.org/10.1016/j.joen.2015.07.010.

\section{References}

1 Al-Sudani D, Grande NM, Plotino G, et al. Cyclic fatigue of nickel-titanium rotary instruments in a double (S-shaped) simulated curvature. J Endod 2012;38: 987-9 .

2 Bhagabati N, Yadav S, Talwar S. An in vitro cyclic fatigue analysis of different endodontic nickel-titanium rotary instruments. J Endod 2012;38:515-8 .

$3 \mathrm{Li}$ UM, Lee BS, Shih CT, et al. Cyclic fatigue of endodontic nickel titanium rotary instruments: static and dynamic tests. J Endod 2002;28:448-51 .

4 Lopes HP, Gambarra-Soares T, Elias CN, et al. Comparison of the mechanical properties of rotary instruments made of conventional nickel-titanium wire, M-wire, or nickel-titanium alloy in R-phase. J Endod 2013;39:516-20 .

5 Anderson ME, Price JW, Parashos P. Fracture resistance of electropolished rotary nickel-titanium endodontic instruments. J Endod 2007;33:1212-6 .

6 Spili P, Parashos P, Messer HH. The impact of instrument fracture on outcome of endodontic 
treatment. J Endod 2005;31:845-50 .

7 Berutti E, Negro AR, Lendini M, Pasqualini D. Influence of manual preflaring and torque on the failure rate of ProTaper rotary instruments. J Endod 2004;30:228-30 .

8 Berutti E, Cantatore G, Castellucci A, et al. Use of nickel-titanium rotary PathFile to create the glide path: comparison with manual preflaring in simulated root canals. J Endod 2009;35:408-12 .

9 Pati n o PV, Biedma BM, Lie bana CR, et al. The influence of a manual glide path on the separation rate of NiTi rotary instruments. J Endod 2005;31:114-6.

10 Sattapan B, Nervo GJ, Palamara JE, Messer HH. Defects in rotary nickel-titanium files after clinical use. J Endod 2000;26:161-5 .

11 Lopes HP, Ferreira AA, Elias CN, et al. Influence of rotational speed on the cyclic fatigue of rotary nickel-titanium endodontic instruments. J Endod 2009;35:1013-6 .

12 Parashos P, Gordon I, Messer HH. Factors influencing defects of rotary nickel-titanium endodontic instruments after clinical use. J Endod 2004;30:722-5 .

13 Cheung GS, Peng B, Bian Z, et al. Defects in ProTaper S1 instruments after clinical use: fractographic examination. Int Endod J 2005;38:802-9 .

14 Peng B, Shen Y, Cheung GS, Xia TJ. Defects in ProTaper S1 instruments after clinical use: longitudinal examination. Int Endod J 2005;38:550-7 .

15 Bouska J, Justman B, Williamson A, et al. Resistance to cyclic fatigue failure of a new endodontic rotary file. J Endod 2012;38:667-9 .

16 Yum J, Cheung GS, Park JK, et al. Torsional strength and toughness of nickel-titanium rotary files. J Endod 2011;37:382-6.

17 Pirani C, Cirulli PP, Chersoni S, et al. Cyclic fatigue testing and metallographic analysis of nickel-titanium rotary instruments. J Endod 2011;37:1013-6 .

18 Elnaghy AM, Elsaka SE. Assessment of the mechanical properties of ProTaper Next nickel-titanium rotary files. J Endod 2014;40:1830-4 .

19 Shen Y, Qian W, Abtin H, et al. Fatigue testing of controlled memory wire nickel-titanium rotary instruments. J Endod 2011;37:997-1001 .

20 Gao Y, Gutmann JL, Wilkinson K, et al. Evaluation of the impact of raw materials on the fatigue and mechanical properties of ProFile Vortex rotary instruments. J Endod 2012;38:398-401 .

21 Johnson E, Lloyd A, Kuttler S, Namerow K. Comparison between a novel nickel-titanium alloy and 508 nitinol on the cyclic fatigue life of ProFile 25/.04 rotary instruments. J Endod 2008;34:1406-9 .

22 Plotino G, Grande NM, Cordaro M, et al. A review of cyclic fatigue testing of nickel-titanium rotary instruments. J Endod 2009;35:1469-76 .

23 Berutti E, Chiandussi G, Gaviglio I, Ibba A. Comparative analysis of torsional and bending stresses in two mathematical models of nickel-titanium rotary instruments: ProTaper versus ProFile. J Endod 2003;29:15-9.

$24 \mathrm{Xu}$ X, Eng M, Zheng Y, Eng D. Comparative study of torsional and bending properties for six models of nickel-titanium root canal instruments with different cross-sections. J Endod 2006;32:372-5 .

25 Kim HC, Kim HJ, Lee CJ, et al. Mechanical response of nickel-titanium instruments with different cross-sectional designs during shaping of simulated curved canals. Int Endod J 2009;42:593-602.

26 Montalv a o D, Shengwen Q, Freitas M. A study on the influence of Ni-Ti M-Wire in the flexural fatigue life of endodontic rotary files by using finite element analysis. Mater Sci Eng C Mater Biol Appl 2014;40:172-9.

27 Lee MH, Versluis A, Kim BM, et al. Correlation between experimental cyclic fatigue resistance and numerical stress analysis for nickel-titanium rotary files. J Endod 2011;37:1152-7 .

28 Auricchio F, Taylor RL, Lubliner J. Shape-memory alloys: macromodelling and numerical simulations of the superelastic behavior. Computer Methods Appl Mech Engrg 1997;146:281-312 . 29 LS-DYNA. Theory Manual. Livermore Software Technology Corporation (LSTC). Livermore, 
CA.

30 Carpinteri A, Spagnoli A, Vantadori S, Bagni C. Structural integrity assessment of metallic components under multiaxial fatigue: the $\mathrm{C}-\mathrm{S}$ criterion and its evolution. Fatigue Fract Engng Mater Struct 2013;36:870-83 .

31 Bahia MG, Melo MC, Buono VT. Influence of cyclic torsional loading on the fatigue resistance of K3 instruments. Int Endod J 2008;41:883-91 .

32 Bahia MG, Martins RC, Gonzalez BM, Buono VT. Physical and mechanical characterization and the influence of cyclic loading on the behaviour of nickel-titanium wires employed in the manufacture of rotary endodontic instruments. Int Endod J 2005;38:795-801 .

33 Chang YZ, Liu MC, Pai CA, et al. Application of non-destructive impedance-based monitoring technique for cyclic fatigue evaluation of endodontic nickel-titanium rotary instruments. Med Eng Phys 2011;33:604-9 .

34 Lopes HP, Elias CN, Vieira VT, et al. Effects of electropolishing surface treatment on the cyclic fatigue resistance of BioRace nickel-titanium rotary instruments. J Endod 2010;36:1653-7 . 35 Viana AC, Pereira ES, Bahia MG, Buono VT. The influence of simulated clinical use on the flexibility of rotary ProTaper Universal, K3 and EndoSequence nickel-titanium instruments. Int Endod J 2013;46:855-62.

\section{Figures}

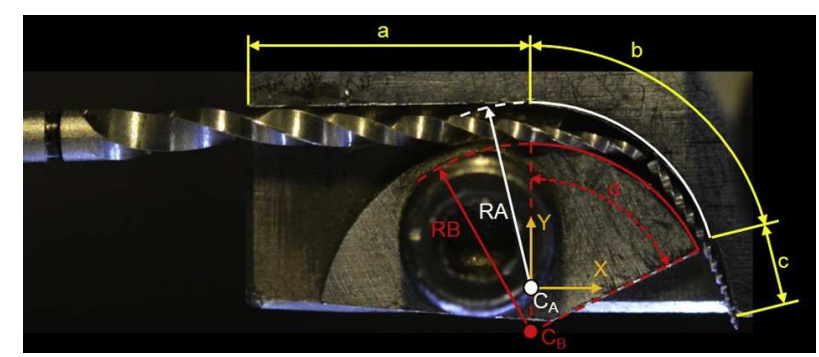

Figure 1. A scheme of the device used for cyclic bending fatigue testing of investigated files; the testing device with its main dimensions as reported in Table 1. a, contact angle; a, initial straight portion of the canal; $b$, curved portion of the canal; $c$, final straight portion of the canal; CA, center of the osculating circle for the outer canal wall; $\mathrm{CB}$, center of the osculating circle for the inner canal wall; $\mathrm{p}$, canal depth; RA, radius of the osculating circle for the outer canal wall; RB, radius of the osculating circle for the inner canal wall; X,Y, reference system.

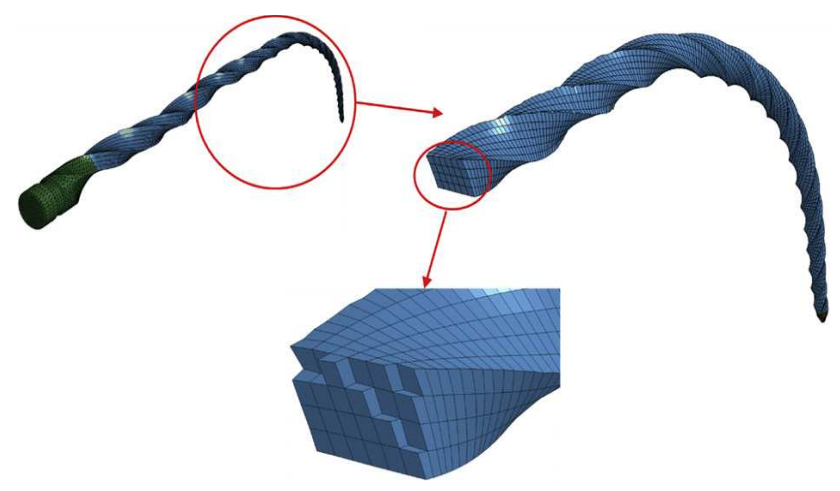

Figure 2. Finite element model of the PTN X1 file. 

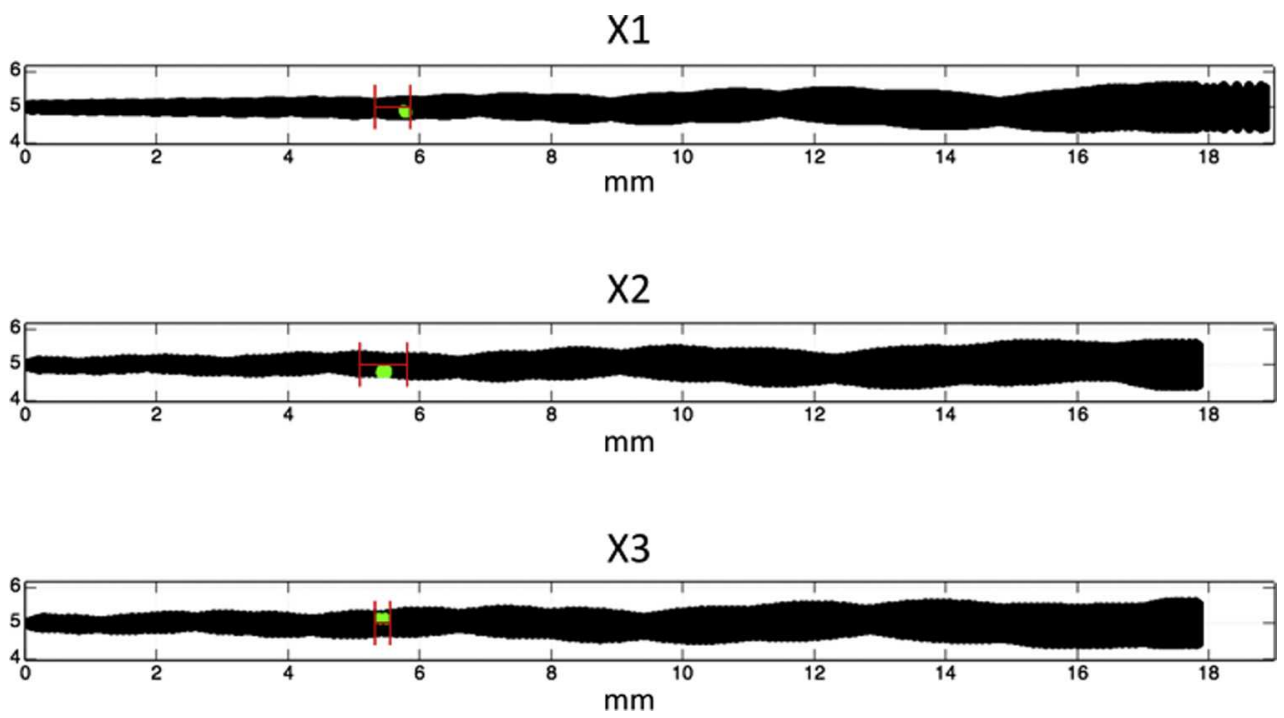

Figure 3. Comparison between FEA and experimental failure locations; vertical red lines denote $95 \%$ confidence intervals for the experimental failure locations, and highlighted green points denote the location of the element with the smallest NCF.

\section{Tables}

TABLE 1. Testing Configurations Adopted for Each Investigated File

\begin{tabular}{lcr} 
Dimensions & X1 & X2, X3 \\
\hline RA [mm] & 5 & 5 \\
RB [mm] & 4.6 & 4.6 \\
Alpha [ $\square]$ & 78 & 78 \\
a [mm] & 6 & 6 \\
b [mm] & 7 & 7 \\
c [mm] & 1 & 1 \\
p [mm] & 0.6 & 0.8 \\
XCB [mm] & +0.18 & +0.04 \\
YCB [mm] & $\square 0.04$ & $\square 0.45$
\end{tabular}

TABLE 2. Main Results of the Analyses

\begin{tabular}{lllrlll}
\hline \multicolumn{2}{l}{ Cyclic fatigue test } & & \multicolumn{2}{l}{ FEA } & \multicolumn{2}{c}{ P value } \\
\hline Instrument & NCF & Fracture length* & NCF & $\begin{array}{l}\text { Fracture } \\
\text { length }\end{array}$ & NCF & $\begin{array}{l}\text { Fracture } \\
\text { length }\end{array}$ \\
\hline & $671 \square 170$ & $5.59 \square 0.38$ & 605 & & & \\
& {$[592 ; 751] 522$} & {$[5.41 ; 5.79] 5.46$} & 518 & 5.775 .46 & & \\
X1 X2 X3 & $\square 67.2[491 ;$ & $\square 0.50[5.23 ;$ & 329 & 5.40 & .10 .89 .78 & .15 .99 .48
\end{tabular}




$$
\text { 553] } 334 \square 61.1 \quad 5.69] 5.44 \square 0.16
$$

$[305 ; 362] \quad[5.37 ; 5.51]$

FEA, finite element analysis; NCF, number of cycles to failure.

Mean $\square$ standard deviation; in square brackets, 95\% confidence interval for the mean.

*Length and location from the file tip in mm (mean $\square \mathrm{SD}$ ). 